Dieses Dokument ist eine Zweitveröffentlichung (Verlagsversion) / This is a self-archiving document (published version):

T. Erdmann, J. Back, R. Tkachov, A. Ruff, B. Voit, S. Ludwigs, A. Kiriy

Dithienosilole-based all-conjugated block copolymers synthesized by a combination of quasiliving Kumada and Negishi catalyst-transfer polycondensations

Erstveröffentlichung in / First published in:

Polymer Chemistry. 2014, 5(18), S. 5383-5390 [Zugriff am: 04.11.2019]. Royal Society of Chemistry. ISSN 1759-9962.

DOI: https://doi.org/10.1039/c4py00747f

Diese Version ist verfügbar / This version is available on:

https://nbn-resolving.org/urn:nbn:de:bsz:14-qucosa2-364240

„Dieser Beitrag ist mit Zustimmung des Rechteinhabers aufgrund einer (DFGgeförderten) Allianz- bzw. Nationallizenz frei zugänglich."

This publication is openly accessible with the permission of the copyright owner. The permission is granted within a nationwide license, supported by the German Research Foundation (abbr. in German DFG).

www.nationallizenzen.de/ 


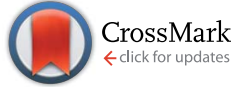

Cite this: Polym. Chem., 2014, 5, 5383

\title{
Dithienosilole-based all-conjugated block copolymers synthesized by a combination of quasi- living Kumada and Negishi catalyst-transfer polycondensations $\dagger$
}

\begin{abstract}
T. Erdmann, ${ }^{\text {ac }}$ J. Back, ${ }^{\text {b R. Tkachov, }}{ }^{a}$ A. Ruff, ${ }^{b}$ B. Voit, ${ }^{\text {ac }}$ S. Ludwigs ${ }^{\star b}$ and A. Kiriy ${ }^{\star a}$
Herein, we present a quasi-living Negishi-type catalyst-transfer polycondensation of a zinc-organic DTSbased monomer which provides an access to narrowly distributed poly(4,4-bis(2-ethylhexyl)dithieno[3,2$\left.b: 2^{\prime}, 3^{\prime}-d\right]$ silole (PDTS) with controlled molecular weight. The synthesis of well-defined all-conjugated diblock copolymers containing a PDTS block was accomplished by a combination of Kumada and Negishi catalyst-transfer polycondensations (KCTP and NCTP, respectively). Particularly, it was shown that living P3HT chains obtained by KCTP of magnesium-organic thiophene-based monomer efficiently initiate NCTP of zinc-organic DTS-based monomer. The purity of the DTS-based monomer was found to be a crucial factor for achieving a clean chain-growth polymerization process. A combination of physico-chemical methods was used to prove the success of the block copolymerization.
\end{abstract}

Received 27th May 2014 Accepted 28th May 2014

DOI: $10.1039 / c 4 p y 00747 f$

www.rsc.org/polymers broadly distributed polymers which makes the preparation of high-quality block copolymers difficult. ${ }^{17}$

In 2004/2005, McCullough et al. ${ }^{18,19}$ and Yokozawa et al. ${ }^{20,21}$ introduced an alternative chain-growth approach to conjugated polymers known as Grignard metathesis (GRIM) polymerization, or Kumada catalyst transfer polycondensation (KCTP). ${ }^{22-26}$ In the case of thiophene-based and some other monomers, e.g. selenophene-based ones, ${ }^{27}$ GRIM polymerization/KCTP involves a quasi-living mechanism and results in polymers with narrow dispersities and well-defined chain ends. ${ }^{22-26}$ Besides polythiophenes, several other well-defined conjugated polymers, including polyfluorenes, ${ }^{28-31}$ polyphenylenes $^{32}$ and polypyrroles $^{32}$ were synthesized. Furthermore, a number of allconjugated block copolymers (BCPs), ${ }^{28-30,32}$ gradient copolymers $^{33}$ and polymer brushes, ${ }^{34-36}$ have been prepared by the sequential polymerization of various monomers. Despite of such progress, chain-growth polycondensations are up to now mostly limited to the polymerization of relatively simple monomers. Recently, Kiriy et al. discovered a new chain-growth polycondensation of complex electron-deficient monomers and this finding paves a way to many useful donor-acceptor copolymers. $^{37,38}$ Aiming at further extension of the scope of chaingrowth polycondensations, we and others were interested to explore the catalyst-transfer polycondensation of DTS-based and related monomers. Very recently, during the preparation of the present work, ${ }^{38}$ Boon et al. reported the KCTP of a DTS-based magnesium-organic monomer into the corresponding homopolymer and a block copolymer containing DTS- and thiophenebased units. ${ }^{39}$ Willot et al. reported the KCTP of a structurally related monomer comprising a cyclopentadithiophene (CPDT)

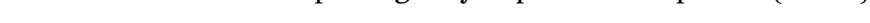

\footnotetext{
${ }^{a}$ Leibniz-Institut für Polymerforschung Dresden e. V. Hohe Straße 6, 01069 Dresden, Germany.E-mail: erdmann@ipfdd.de; kiriy@ipfdd.de

${ }^{b}$ University of Stuttgart, IPOC-Functional Polymers, Pfaffenwaldring 55, 70569 Stuttgart, Germany. E-mail: sabine.ludwigs@ipoc.uni-stuttgart.de

'Technische Universität Dresden, Center for Advancing Electronics Dresden and Chair of Organic Chemistry of Polymers, 01062 Dresden, Germany

$\dagger$ Electronic supplementary information (ESI) available: Materials and methods, synthetic procedures, NMR spectra, GPC profiles and experimental results for HT-GPC, DSC, UV/Vis, CV and AFM. See DOI: 10.1039/c4py00747f
}

Conjugated polymers are a promising class of materials for
organic electronics. The synthesis of semiconducting polymers with a high hole mobility, air stability and solution processability is an important step in the development of low-cost
printed optoelectronic components, such as organic lightemitting diodes (OLEDs), ${ }^{1-4}$ photovoltaic cells (OPVs) ${ }^{5-7}$ or fieldcopolymers came into the focus of interest because of their unique combination of self-assembly properties useful for HOMO and LUMO energy levels. ${ }^{12}$ Among the silicon-containing $\pi$-conjugated building blocks for conjugated polymers as $\pi$-donor substructure due to its stability in ambient atmo-
athons sphere..$^{6,713-15}$ Ohshita et al. ${ }^{16}$ applied an anodic polymerization of a DTS-based monomer, however this method suffers from based homopolymers were synthesized by means of step-growth Stille coupling polycondensation, but this method leads to
\end{abstract}


unit. ${ }^{40}$ However, only a moderate chain-growth polymerization performance was achieved in these polymerizations regarding the fact that relatively broadly distributed DTS- and CPDT-based homopolymers and block copolymers were obtained.

Herein, we present a quasi-living Negishi-type catalysttransfer polycondensation of zinc-organic DTS-based monomers into narrowly distributed poly(4,4-bis(2-ethylhexyl) dithieno[3,2-b:2', $\left.3^{\prime}-d\right]$ silole) (PDTS). The synthesis of welldefined all-conjugated diblock copolymers containing a PDTS block was accomplished by a combination of Kumada and Negishi catalyst-transfer polycondensations (KCTP and NCTP, respectively). Particularly, we show that living P3HT chains obtained by the KCTP of the magnesium-organic thiophenebased monomer efficiently initiate the NCTP of the zincorganic DTS-based monomer. The purity of the DTS-based monomer was found to be a crucial factor for achieving a clean chain-growth polymerization process. An extensive physicochemical characterization of the resulting P3HT- $b$-PDTS BCPS including optical, electrochemical and morphological properties is also reported.

\section{Experimental}

(6-Bromo-4,4-bis(2-ethylhexyl)dithieno[3,2-b:2' $3^{\prime}$ - $\left.d\right]$ silol-2-yl)zinc(II) chloride (5)

$n$-Butyllithium (0.34-0.36 mL, 0.84-0.89 mmol, 0.9-0.95 eq., 2.5 $\mathrm{M}$ in hexanes) was added to a solution of dibromide $3(0.54 \mathrm{~g}$, $0.93 \mathrm{mmol}, 1$ eq.) in dry THF $(20 \mathrm{~mL})$ under nitrogen atmosphere at $-100{ }^{\circ} \mathrm{C}$. After $30 \mathrm{~min}$ a solution of anhydrous zinc(II) chloride $(0.20 \mathrm{~g}, 1.5 \mathrm{mmol}, 1.6 \mathrm{eq}$.) in dry THF $(10 \mathrm{~mL})$ was added via syringe and the mixture was stirred for $15 \mathrm{~min}$ at $-100{ }^{\circ} \mathrm{C}$ and after warming up with a water bath, for additional $1 \mathrm{~h}$ at room temperature. To investigate the monometalization yield by GC/MS, $1 \mathrm{~mL}$ of the reaction mixture was quenched with $2 \mathrm{~mL}$ of $\mathrm{MeOH}$, diluted with $\mathrm{CHCl}_{3}$, washed with water and dried over $\mathrm{MgSO}_{4}$. Finally, the solvents were removed under reduced pressure. It was found that the conversion of 3 into 5 is $\sim 100 \%$.

\section{PDTS}

Different feed molar ratios of the initiator phenyl-(1,2-bis(diphenylphosphino)ethane)nickel bromide, $\mathrm{PhNi}(\mathrm{dppe}) \mathrm{Br}$, and of the monomer 5 were set $(1: 20,1: 30,1: 50)$. The typical synthesis procedure (feed molar ratio $1: 50$ ) is as follows: PhNi(dppe) $\mathrm{Br}$ (3.2 mg, $5.2 \mu \mathrm{mol}, 1$ eq.) was dissolved in dry THF $(3 \mathrm{~mL})$ and transferred into a dried flask with nitrogen atmosphere. The freshly prepared solution of $\mathbf{5}$ (synthesized from $0.15 \mathrm{~g}(0.26 \mathrm{mmol}, 50 \mathrm{eq}$.) of 3$)$ was added via syringe at $0{ }^{\circ} \mathrm{C}$ and the colour changed immediately to dark violet. After $30 \mathrm{~min}$ the polymerization was quenched by adding $5 \mathrm{M} \mathrm{HCl}(1 \mathrm{~mL})$ and the reaction mixture was afterwards poured into water. The organic phase was washed with water, dried over $\mathrm{MgSO}_{4}$ and solvents were removed under reduced pressure. The raw polymers were purified via Soxhlet extraction with methanol, acetone and hexane. The residual was collected with dichloromethane, resulting in $40 \mathrm{mg}$ (37\%) of a dark violet to bluish solid (GPC:
$\left.M_{\mathrm{n}}=25000 \mathrm{~g} \mathrm{~mol}^{-1}, M_{\mathrm{w}}=40000 \mathrm{~g} \mathrm{~mol}^{-1}, M_{\mathrm{w}} / M_{\mathrm{n}}=1.60\right) .{ }^{1} \mathrm{H}-$ NMR (500 MHz, $\left.\mathrm{C}_{2} \mathrm{D}_{2} \mathrm{Cl}_{4}, 393 \mathrm{~K}, \delta[\mathrm{ppm}]\right): 7.64,7.41,7.29,7.25$, 7.17, 7.11, 1.55, 1.45-1.17, 1.15-1.03, 1.00-0.80.

\section{Synthesis of P3HT- $b$-PDTS}

A series of BCPs was prepared based on different feed molar ratios of the initiator $\mathrm{PhNi}(\mathrm{dppe}) \mathrm{Br}$, the 3-hexylthiophene monomer 7 and 5. A typical procedure with the feed molar ratio $1: 50: 15$ is described below. A solution of the monomer 7 (solution A) was prepared by dissolving 2-bromo-3-hexyl-5iodothiophene (6) $(100 \mathrm{mg}, 0.27 \mathrm{mmol}, 50$ eq.) in dry THF (4 $\mathrm{mL})$, adding tert-butylmagnesium chloride $(t$-BuMgCl$)$ solution (0.27 mL, $0.27 \mathrm{mmol}, 50$ eq., $1.0 \mathrm{M}$ in THF) at $0{ }^{\circ} \mathrm{C}$ and stirring it for $2 \mathrm{~h}$. The solution of 5 (solution B) was synthesized as described above by using $46 \mathrm{mg}$ ( $0.08 \mathrm{mmol}, 15$ eq.) of 3 . Under nitrogen atmosphere, a solution of $\mathrm{PhNi}$ (dppe)Br (3.3 mg, 5.4 $\mu \mathrm{mol}, 1$ eq. $)$ in dry THF ( $1 \mathrm{~mL})$ was cooled to $0{ }^{\circ} \mathrm{C}$ and solution $\mathrm{A}$ was added in one portion. After stirring for $15 \mathrm{~min}$, a small sample was taken to investigate the P3HT block and quenched with $5 \mathrm{M} \mathrm{HCl}(0.1 \mathrm{~mL})$. Afterwards, solution B was added in one portion via syringe and the resulting solution was stirred for another $15 \mathrm{~min}$. The reaction was quenched by adding $5 \mathrm{M} \mathrm{HCl}$ $(1 \mathrm{~mL})$ followed by the addition of $\mathrm{CHCl}_{3}$ and water. The organic phase was washed with water and dried over $\mathbf{M g S O}_{4}$. After removing the solvents the sample was purified using Soxhlet extraction with methanol, acetone and hexane. The residual was collected with dichloromethane, resulting in $17 \mathrm{mg}(20 \%)$ of a dark violet solid (GPC: $M_{\mathrm{n}}=8000 \mathrm{~g} \mathrm{~mol}^{-1}, M_{\mathrm{w}}=10400 \mathrm{~g} \mathrm{~mol}^{-1}$, $\left.M_{\mathrm{w}} / M_{\mathrm{n}}=1.30\right)$. The P3HT homopolymer sample was diluted with chloroform, washed with water and dried with $\mathrm{MgSO}_{4}$. The solvents were removed under reduced pressure, yielding a darkred solid (GPC: $M_{\mathrm{n}}=3500 \mathrm{~g} \mathrm{~mol}^{-1}, M_{\mathrm{w}}=4000 \mathrm{~g} \mathrm{~mol}^{-1}, M_{\mathrm{w}} / M_{\mathrm{n}}$ = 1.15). ${ }^{1} \mathrm{H}-\mathrm{NMR}\left(500 \mathrm{MHz}, \mathrm{C}_{2} \mathrm{D}_{2} \mathrm{Cl}_{4}, 393 \mathrm{~K}, \delta[\mathrm{ppm}]\right): 7.60,7.38$, $7.29,7.16,7.20-7.07,6.98,2.81,1.71,1.50-1.07,1.00,0.92,0.88-$ 0.70 .

\section{Results and discussion}

\section{Monomer preparation}

The dibrominated DTS precursor monomer 3 was synthesized by a two-step procedure starting from 2-bromothiophene (1) (Scheme 1). In the first step, 1 was successively silylated and dimerized according to an existing literature procedure. ${ }^{41}$ The protection of the 5-position of $\mathbf{1}$ by silylation was necessary to ensure a clean base-catalyzed halogen dance (BCHD) reaction, upon the addition of the second lithium diisopropylamide (LDA) portion, followed by the oxidative coupling with $\mathrm{CuCl}_{2}$ to the bithiophene 2 . In the second step, the dithieno[3,2-b:2', $\left.3^{\prime}-d\right]$ silole heterocycle was formed by lithiation with $n$-butyllithium ( $n$-BuLi) and the addition of dichlorobis(2-ethylhexyl)silane, as well as the subsequent bromination with $\mathrm{N}$-bromosuccinimide (NBS). With this procedure, the precursor monomer 3 was obtained with a high degree of purity in an over-all yield of $59 \%$. A standard GRIM reaction was firstly tested for the preparation of monomer 4 because it is usually the simplest method for the synthesis of various thiophenic monomers suitable for KCTP. 


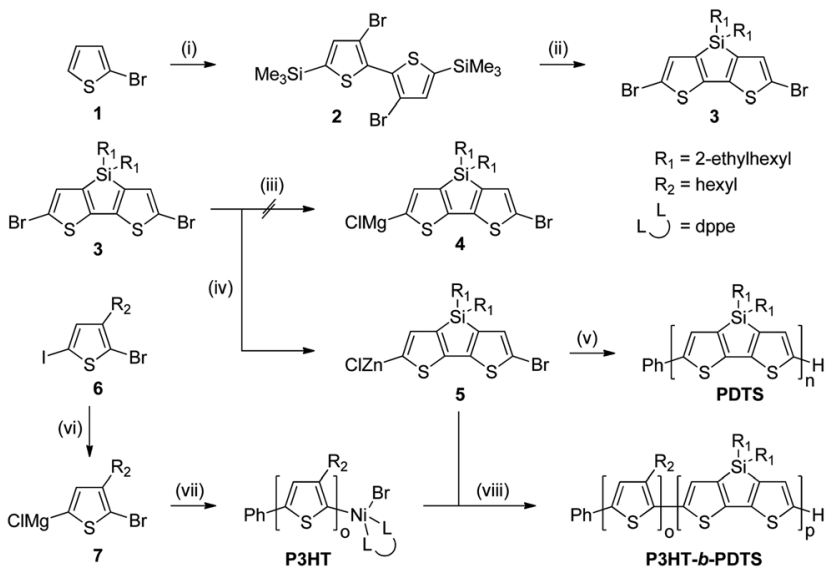

Scheme 1 Preparation of DTS monomer, PDTS homopolymer and PDTS-based block copolymers. Reaction conditions: (i): (a) LDA, -78 ${ }^{\circ} \mathrm{C}$. (b) $\mathrm{TMSCl},-78^{\circ} \mathrm{C}$. (c) $\mathrm{LDA},-78^{\circ} \mathrm{C}$ (BCHD). (d) $\mathrm{CuCl}_{2},-78^{\circ} \mathrm{C}$ to r.t. $78 \%$. (ii): (a) $n$-BuLi, $-100^{\circ} \mathrm{C}$. (b) $\left(\mathrm{R}_{1}\right)_{2} \mathrm{SiCl}_{2},-100^{\circ} \mathrm{C}$ to r.t. (c) $\mathrm{NBS}, 0^{\circ} \mathrm{C}$ $75 \%$. (iii): $t-\mathrm{BuMgCl},-78{ }^{\circ} \mathrm{C}$ to r.t. (iv): (a) $n-\mathrm{BuLi},-100{ }^{\circ} \mathrm{C}$. (b) $\mathrm{ZnCl}_{2}$, $-100{ }^{\circ} \mathrm{C}$ to r.t. (v): (a) $\mathrm{PhNi}(\mathrm{dppe}) \mathrm{Br}, 0^{\circ} \mathrm{C}$. (b) $\mathrm{HCl}$. (vi): $t-\mathrm{BuMgCl}, 0^{\circ} \mathrm{C}$ to r.t. (vii): $\mathrm{PhNi}(\mathrm{dppe}) \mathrm{Br}, \mathrm{O}^{\circ} \mathrm{C}$. (viii): (a) $0^{\circ} \mathrm{C}$. (b) $\mathrm{HCl}$.

As GC/MS and NMR analysis of the GRIM reaction mixtures quenched with methanol reveal, the halogen/magnesium exchange between 3 and $t$-BuMgCl proceeds very slowly at room as well as at elevated temperatures, so that yields of the target monomer 4 were always low in these experiments. The "TurboGrignard" reagent, $i$-PrMgCl : $\mathrm{LiCl},{ }^{42}$ reacted with an equimolar amount of $\mathbf{3}$ much faster than ordinary Grignard reagents, ${ }^{\mathbf{4 0}}$ however the yield of $\mathbf{4}$ never exceeded $90 \%$, in accordance with a previous report of Boon et al. ${ }^{39}$ Consequently, substantial amounts of unreacted $i$-PrMgCl $: \mathrm{LiCl}$ remained in the reaction mixture in these experiments. The presence of rather large amounts of the Grignard reagent is undesirable for a clean chain-growth polymerization because Grignards react readily with propagating chains terminating them which results into a broadening of the dispersity $\left(\bigoplus_{\mathrm{M}}=M_{\mathrm{w}} / M_{\mathrm{n}}\right)$ and a decrease of the degree of polymerization (DP) relative to the theoretically reachable level. ${ }^{39}$

Aiming at an increase of the monomer purity and, accordingly, at an improvement of the chain-growth performance, a more reactive halogen-metal exchange agent, $n$-BuLi, was used in this work. An advantage of $n$-BuLi compared to both Grignard and Turbo-Grignard reagents is that it reacts quantitatively with 3 by using an equimolar amount and no unreacted $n$-BuLi (which is a potent chain terminator) is left in the reaction mixture. The zinc-organic monomer $\mathbf{5}$ with a purity above $99 \%$ was obtained by the treatment of 3 with a slight lack of $n-\mathrm{BuLi}$ (0.9-0.95 eq.) at cryogenic temperatures, followed by the addition of anhydrous $\mathrm{ZnCl}_{2}$. Cryogenic temperatures down to -100 ${ }^{\circ} \mathrm{C}$ and a slight excess of $\mathbf{3}$ were found to be crucial for suppressing the formation of dimetalated DTS molecules, a potential chain-termination agent. On the other hand, unreacted dibromide 3 did not influence negatively the chain-growth polymerization performance, as it was observed earlier in other catalyst-transfer polycondensations. ${ }^{22-26}$ It is also noteworthy that using an excess of $\mathrm{ZnCl}_{2}$ of $60 \mathrm{~mol} \%$ relative to $n$-BuLi was found to be beneficial for a complete $\mathrm{Li}-\mathrm{Zn}$ exchange and achieving a better polymerization control.

\section{Homopolymerization}

The polymerization of $\mathbf{5}$ (Scheme 1) was initiated by the addition of an ex situ prepared initiator PhNi(dppe)Br. Depending on the ratio of $5 / \mathrm{PhNi}(\mathrm{dppe}) \mathrm{Br}$, PDTS with number average molecular weights $\left(M_{\mathrm{n}}\right)$ in the range of 4000 to $25000 \mathrm{~g} \mathrm{~mol}^{-1}$ and relatively narrow dispersities $\left(M_{\mathrm{w}} / M_{\mathrm{n}}=D_{\mathrm{M}}\right)$ were obtained $\left(M_{\mathrm{n}}=4000 \mathrm{~g} \mathrm{~mol}^{-1}, \emptyset_{\mathrm{M}}=1.1 ; M_{\mathrm{n}}=12000 \mathrm{~g} \mathrm{~mol}^{-1}, Ð_{\mathrm{M}}=1.4\right.$; $\left.M_{\mathrm{n}}=25000 \mathrm{~g} \mathrm{~mol}^{-1}, \oplus_{\mathrm{M}}=1.6\right)$.

When conducted at room temperature, the polymerization proceeded very fast and was almost over in $10 \mathrm{~min}$ (Fig. S3†). To slow the polymerization rate and to monitor the polymer growth, the temperature was decreased to $-30{ }^{\circ} \mathrm{C}$. In this case, samples were taken from a polymerization mixture at different reaction times and analysed by GPC. By plotting the resulting $M_{\mathrm{n}}$ of each sample against the reaction time it can be seen that the molecular weight increases very fast at the beginning before reaching a plateau (Fig. 1a), which is not the case in step-growth polycondensations, for which $M_{\mathrm{n}}$ increases abruptly at later polymerization stages. A very similar behavior was observed by Lohwasser and Thelakkat ${ }^{43}$ for the chain-growth KCTP of P3HT using McCullough conditions.

Additionally, it was found that $M_{\mathrm{n}}$ increases linearly with increasing the monomer/initiator feed ratio $[5]_{0} /[\mathrm{PhNi}(\mathrm{dppe}) \mathrm{Br}]$ (Fig. 1b). The ${ }^{1} \mathrm{H}$ NMR spectra confirmed the successful initiation by $\mathrm{PhNi}(\mathrm{dppe}) \mathrm{Br}$ because of the existence of signals
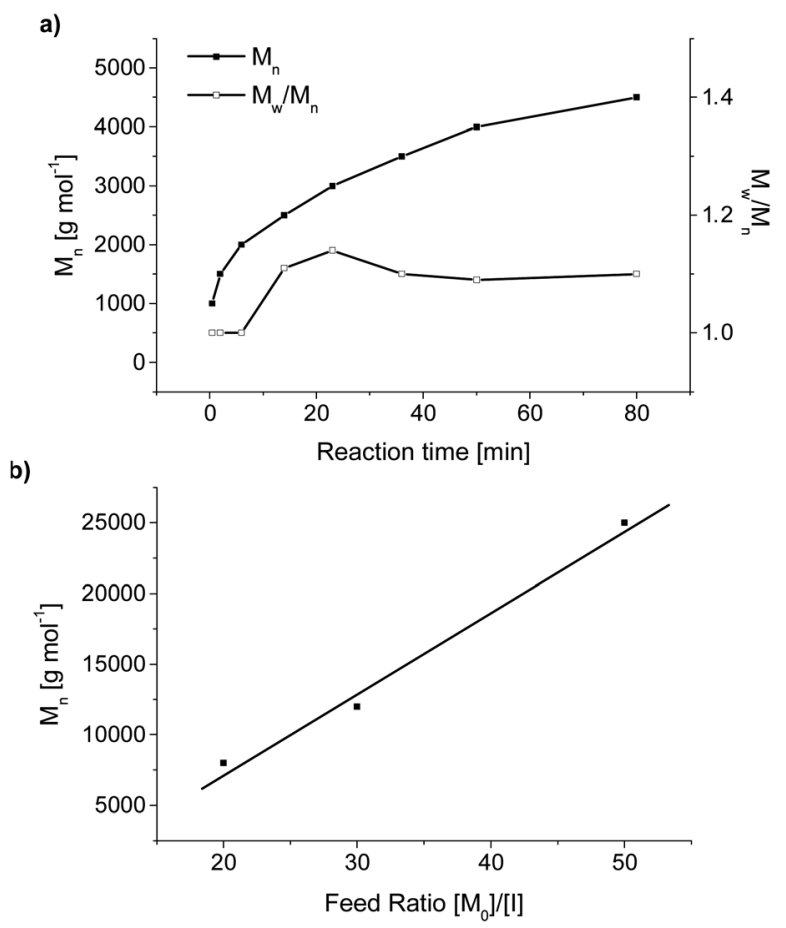

Fig. 1 Synthesis of PDTS via NCTP: number-average molecular weight $M_{n}$ versus reaction time plot at $-30{ }^{\circ} \mathrm{C}$ (a) and resulting final $M_{n}$ versus feed ratio plot (b). 
belonging to phenyl groups bonded to the chains as a starting moiety. However, quantitative evaluation of the initiation degree from the Ph-based initiator was difficult because of overlap of the $\mathrm{H}$ end-group signals and main polymeric signals (Fig. S1†).

Thus, the Ni-catalyzed polycondensation of zinc-organic monomer 5 allows a good control over molecular weight, molecular weight distribution and endgroup functionality. With this method, relatively high molecular weight PDTSs with $M_{\mathrm{n}}$ up to $25000 \mathrm{~g} \mathrm{~mol}^{-1}$ and relatively narrow dispersities can be routinely obtained. In comparison to the previously reported PDTSs $^{39}$ and structurally similar PCPDTs, ${ }^{40}$ both synthesized by KCTP, our NCTP procedure enables much more well defined homopolymers regarding polydispersities, with even higher molecular weight PDTSs due to a much cleaner monomer activation procedure. A clean chain-growth homopolymerization of $\mathbf{5}$ was a necessary precondition and a good starting point for the preparation of PDTS-based all-conjugated block copolymers.

\section{Block copolymerization}

In this work, the synthesis of block copolymers comprising PDTS and P3HT blocks was attempted by copolymerization of $\mathbf{5}$ and magnesium-organic thiophenic monomer 7. It was previously shown that the polymerization order of the two monomers influences the block copolymerization behavior if they have significantly different nature. For instance, in the block copolymerization of thiophene- and fluorene-based monomers, the fluorene monomer must be polymerized first. Otherwise a transfer of the $\mathrm{Ni}(0)$ catalyst species from the polythiophene block to the fluorene moiety is precluded due to a weaker $\mathrm{Ni}(0)$ complexing ability of the fluorene compared with the thiophene groups. ${ }^{28-30}$ Because it was a priori not clear what monomer should be polymerized first for achieving the best block copolymerization performance, both monomer addition orders were exploited (Scheme S1 $\dagger$ ). In the first approach, P3HT macroinitiator was synthesized according to Tkachov et $a .^{44}$ and a sample was taken from the reaction mixture to investigate the P3HT starting block. Afterwards a freshly prepared solution of $\mathbf{5}$ was added and the living $\mathrm{P} 3 \mathrm{HT}$ chains immediately initiated the polymerization of the second block. In the GPC profiles the peaks corresponding to increased polymerization times shift to higher molecular weights by maintaining the one-peak shape, indicating a successful block copolymerization without homopolymer formation (Fig. 2a). In order to investigate this more closely, a next series of three P3HT- $b$-PDTS BCPs was synthesized by using the same feed ratio for the P3HT starting block and an increasing amount of added monomer 5 . The collected GPC curves of the unpurified polymers (Fig. 2b) show the reproducible P3HT synthesis $\left(M_{\mathrm{n}}=\sim 3800 \mathrm{~g} \mathrm{~mol}^{-1}, D_{\mathrm{M}}=1.1\right)$ and the complete BCP formation by shifting the well-defined monomodal peaks to higher molecular weights with increasing the amount of $5\left(M_{\mathrm{n}}=8000 / 10000 / 11500 \mathrm{~g} \mathrm{~mol}^{-1}, D_{\mathrm{M}}=1.3 /\right.$ 1.4/1.5). The little broadening in the molecular weight distributions of the BCPs is most likely caused by a chain-termination side reaction with dimetalated DTS molecules. Because of no a)

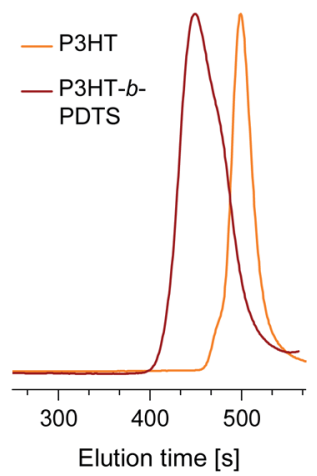

b)

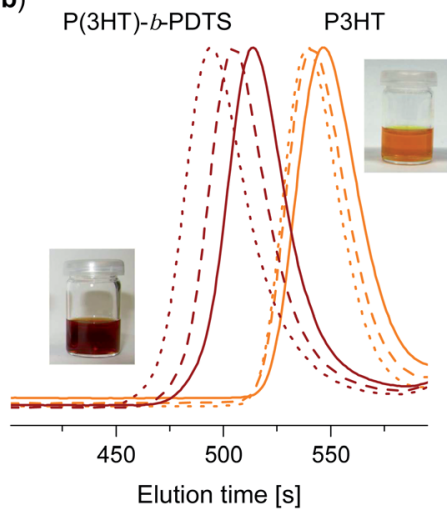

Fig. 2 GPC plots of the starting P3HT macroinitiator and resulting P3HT- $b$-PDTS with fixed (a) and increasing (b) amount of 5 including pictures of THF solutions of the homo- and block copolymers.

shoulders appearing in the GPC curves of the BCPs, a formation of homopolymers can be neglected.

In addition, as seen in the ${ }^{1} \mathrm{H}$ NMR spectra of the BCPs (Fig. S2 $\dagger$ ), the P3HT end-group signals completely disappeared. This means that all living P3HT chain ends reacted with the second monomer and that there is no P3HT homopolymer contamination in the BCP sample. As such, these data suggest that P3HT living chains formed in KCTP process of the magnesium-organic thiophene-based monomer in the presence of $\mathrm{PhNi}(\mathrm{dppe}) \mathrm{Br}$, efficiently initiate Negishi polycondensation of the Zn-organic DTS-monomer which accounts to a well-controlled block copolymerization process.

Importantly, the combination of KCTP and NCTP protocols described herein allows much better control over the block polycondensation process than previously reported in the allKumada polycondensation protocol reported by Boon et al. ${ }^{39}$ as can be deduced from much broader polydispersities of resulting P3HT- $b$-PDTS in that work. ${ }^{39}$ The difference in the chain-growth polycondensation performances in our work with respect to literature $^{39}$ we attribute to a substantially higher monomer purity formed upon the activation process of the used BuLi versus Grignard reagents.

The BCP PDTS- $b$-P3HT $\left(M_{\mathrm{n}}=21000 \mathrm{~g} \mathrm{~mol}^{-1}, D_{\mathrm{M}}=1.8\right.$, block ratio $35: 65)$ was also obtained by using reverse monomer addition order and starting from the polydithienosilole block. The block copolymerization performance was much worse in this case as follows from appearance of a well-pronounced high molecular weight shoulder in the GPC curve of the BCP and broadening of $\bigoplus_{\mathrm{M}}$ (Fig. S4 $\dagger$ ). The poor block copolymerization performance in the case of " 5 -followed-by-7" monomer addition order may be explained by extensive chain-termination reactions which accompany the growth of the PDTS block. Indeed, PDTS chains, terminated before the addition of the second monomer 7, cannot initiate the polymerization of the second monomer which leads to a contamination of the PDTS- $b$-P3HT block copolymer with PDTS homopolymers. On the other hand, the chain-termination of PDTS, occurring at the second polymerization stage affects the BCP quality to a lesser extent because this only leads to a shortening of the second block and 
to a broadening of its molecular weight distribution (which are less critical factors than contamination of the BCP with homopolymers).

Alternatively, the dependence of the block copolymerization result on the order of monomer addition may be explained by a different complexation ability of $\mathrm{Ni}(0)$ catalyst to the $\pi$-conjugated systems constituting the first and the second block. However, as both monomer units have a rather similar nature, it is a priori not clear which monomer has the stronger affinity to $\mathrm{Ni}(0)$. The groups of Yokozawa and Wang suggested that the $\mathrm{Ni}(0)$ species preferentially complexes with the most electronrich unit. ${ }^{28-30,44}$ However, our electrochemistry studies reveal that PDTS and P3HT have very similar oxidation potentials with P3HT being a slightly better electron donating moiety (see below). As such, the explanation based on different complexation ability depending on their electron-richness is less probable in this case.

To further verify a success of the block copolymerization process, in the following paragraphs, we compare the physicochemical properties of one P3HT- $b$-PDTS polymer $\left(M_{\mathrm{w}}=23200\right.$ $\mathrm{g} \mathrm{mol}^{-1}, \emptyset_{\mathrm{M}}=1.98$, HT-SEC in TCB vs. PS) and its corresponding P3HT macroinitiator $\left(M_{\mathrm{w}}=10700 \mathrm{~g} \mathrm{~mol}^{-1}, \bigoplus_{\mathrm{M}}=\right.$ 1.59, HT-SEC vs. PS). A model PDTS homopolymer $\left(M_{\mathrm{w}}=28500\right.$ $\mathrm{g} \mathrm{mol}^{-1}, D_{\mathrm{M}}=1.90$, HT-SEC $v s$. PS) and a physical blend of P3HT : PDTS with the same weight fractions (57:43) of P3HT and PDTS as the block copolymer are also included for comparison reasons.

\section{Optical properties}

Fig. 3 shows the absorption spectra of thin P3HT, PDTS and P3HT- $b$-PDTS films. The absorption spectrum of the thin P3HT film is characterized by a broad absorption band with two vibronic features centred at $605 \mathrm{~nm}\left(\lambda_{0-0}\right)$ and $560 \mathrm{~nm}\left(\lambda_{0-1}\right)$, and is well described in the literature. ${ }^{45,46}$ The spectrum of the PDTS homopolymer in chlorobenzene is dominated by two overlapping main peaks at $570 \mathrm{~nm}$ and a $595 \mathrm{~nm}$ (Fig. S6†). The PDTS film spectrum also exhibits two bands at $550 \mathrm{~nm}$ and 595 $\mathrm{nm}$ and an additional shoulder at $640 \mathrm{~nm}$ which leads to an overall red-shift with respect to the solution spectrum. The

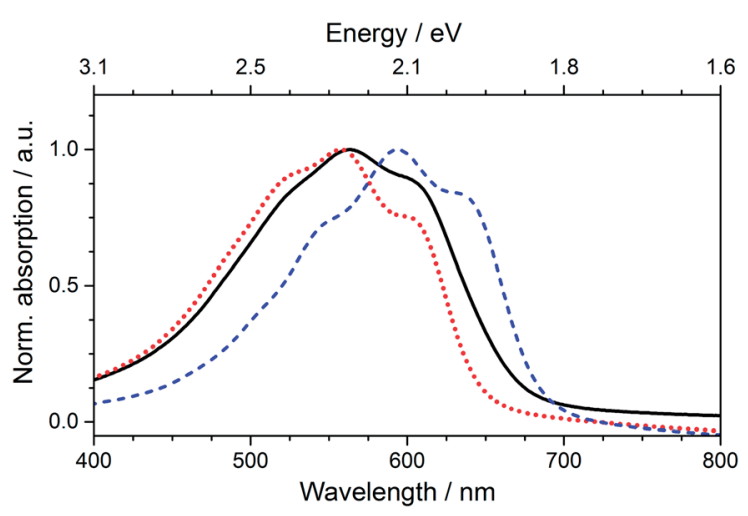

Fig. 3 Absorption spectra of P3HT (red, dotted line), PDTS (blue, dashed line) and block copolymer (black, solid line) films spin-coated from chlorobenzene solution $\left(c=3 \mathrm{~g} \mathrm{~L}^{-1}\right)$ at $1000 \mathrm{rpm}$ for $20 \mathrm{~s}$. spectra are in agreement with the literature. ${ }^{39}$ Similar to P3HT this shoulder at $640 \mathrm{~nm}$ might possibly be related to some kind of aggregation phenomena in the film state.

The solution spectrum of the P3HT- $b$-PDTS block copolymer (Fig. S6 $\dagger$ ) can be regarded as a superposition of the $\mathrm{P} 3 \mathrm{HT}$ and PDTS homopolymer spectra, similarly to the behavior of structurally-related P3HT- $b$-PCPDT reported by Willot et al. ${ }^{40}$ Also the film spectra, Fig. 3, seem to be a superposition of the two homopolymer film spectra. This becomes evident from comparison with a polymer blend with the same weight fractions, Fig. S7, $\uparrow$ and by adding the two separate homopolymer film spectra with different weight factors of P3HT, see Fig. S8. $\dagger$ A strong red-shift of the film spectra is only expected for block copolymers with a PDTS-majority block. The optical band gaps can be estimated from the peak onsets of the respective spectra (Table S4†) to $1.9 \mathrm{eV}$ (P3HT), $1.7 \mathrm{eV}$ (PDTS) and $1.8 \mathrm{eV}$ (BCP).

\section{Electrochemistry}

The electrochemical properties of the homopolymers (P3HT and PDTS) and the block copolymer were investigated by means of cyclic voltammetry in acetonitrile containing $\mathrm{NBu}_{4} \mathrm{PF}_{6}(0.1 \mathrm{M})$ acting as supporting electrolyte (in the following all potentials are given $v s$. the formal potential $E^{0}$ of the standard redox couple ferrocene/ferrocenium $\mathrm{Fc} / \mathrm{Fc}^{+}$(ref. 47)). The homopolymers as well as the block copolymer show chemically reversible oxidation and reduction processes (Fig. $4 \mathrm{a}-\mathrm{c}$ ). The onset potential values for the oxidation $E^{\mathrm{ox}}$ of the homopolymers P3HT and PDTS are $0.1 \mathrm{~V}$ and $0.2 \mathrm{~V}$, respectively. The lower value of $\mathrm{P} 3 \mathrm{HT}$ indicates the stronger electron donor character of this polymer compared to PDTS. The onset value for the BCP is
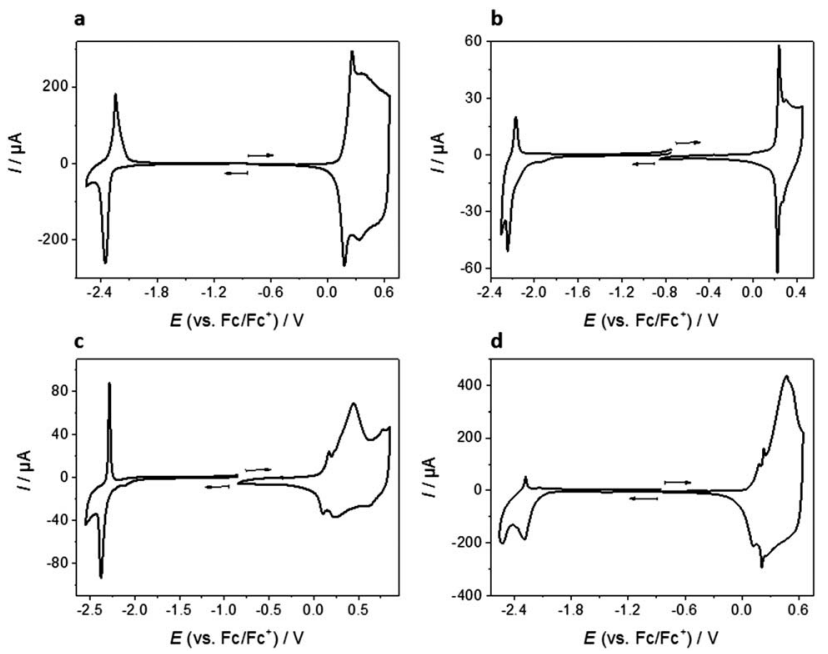

Fig. 4 Cyclic voltammetry of drop cast P3HT, PDTS, BCP and P3HT:PDTS blend films on $\mathrm{Au}$ in $0.1 \mathrm{MNBu}_{4} \mathrm{PF}_{6} / \mathrm{MeCN}$; arrows indicate scan direction; oxidation and reduction cycles were performed separately to avoid charge trapping effects; a: $p$ - (third cycle, $20 \mathrm{mV} \mathrm{s}^{-1}$ ) and $\mathrm{n}$-doping (second cycle, $20 \mathrm{mV} \mathrm{s}^{-1}$ ) process of P3HT; $\mathrm{b}$ : $\mathrm{p}$ - (second cycle, $20 \mathrm{mV} \mathrm{s}^{-1}$ ) and $\mathrm{n}$-doping (third cycle, $50 \mathrm{mV} \mathrm{s}^{-1}$ ) process of PDTS; c: $p$ - (second cycle, $20 \mathrm{mV} \mathrm{s}^{-1}$ ) and $\mathrm{n}$-doping (second cycle, $20 \mathrm{mV} \mathrm{s}^{-1}$ ) process of BCP; d: P3HT:PDTS blend film: first reduction cycle $(20 \mathrm{mV}$ $\left.\mathrm{s}^{-1}\right)$ and second oxidation cycle $\left(20 \mathrm{mV} \mathrm{s}^{-1}\right)$. 
$0.1 \mathrm{~V}$ and corresponds to that of pure P3HT. The onset potential values for the reduction $E^{\text {red }}$ for P3HT and PDTS are $-2.3 \mathrm{~V}$ and $-2.1 \mathrm{~V}$, respectively. For the BCP a value of $-2.3 \mathrm{~V}$ is obtained which again corresponds to that of pure P3HT. Thus, P3HT dominates the redox behavior of the BCP. It should be noted that in the case of P3HT and BCP a strong memory effect ${ }^{48}$ during n-doping is observed. However, after the second cycle the onset potentials remain constant. Thus, for the determination of $E^{\text {red }}$ of P3HT and the BCP the first cycle was neglected. In the case of PDTS, this effect was not observed.

The electrochemical band gaps of P3HT, PDTS and the BCP are estimated to $2.4 \mathrm{eV}, 2.2 \mathrm{eV}$ and $2.4 \mathrm{eV}$, according to Cardona et $a l^{49} \mathrm{~A}$ table summarizing all electrochemical and optical band gaps can be found in the ESI (Table S4 $\dagger$ ).

For comparison, cyclic voltammetric experiments were performed with a blend consisting of analogous weight fractions of P3HT and PDTS as in the BCP. In case of the n-doping process, two reduction waves were observed during the forward scan of the first cycle (Fig. 3d). However, in the backward scan, only one re-oxidation signal is present. This indicates that only one homopolymer can be reversibly n-doped in the blend film system. The onset potential value of the first signal is $-2.1 \mathrm{~V}$ and corresponds to the reduction of PDTS. In the second cycle, only one chemically reversible redox couple is observed with an onset potential of $E^{\text {red }}=-2.4 \mathrm{~V}$ that we assign to the reduction of P3HT. Thus, the PDTS polymer seems to be released from the electrode surface during the first cycle. This is supported by the fact that after the reduction, the voltammogram of the oxidation reveals the shape and onset potential $(0.1 \mathrm{~V})$ of pure P3HT. A visual inspection of a used electrode supports this assumption: only brown-colored polymer patches (presumably of P3HT, PDTS has a blue color) could be detected after n-doping. The oxidation onset potential of the P3HT:PDTS blend was estimated to be $0.0 \mathrm{~V}$ (determined with a freshly prepared electrode). This value is $\Delta=0.1 \mathrm{~V}$ lower than $E^{\mathrm{ox}}$ of pristine P3HT and the BCP. The results indicate that in the case of the BCP, indeed a block copolymer structure is present: in the $I-E$ curves of the blend films signals of both the P3HT and PDTS homopolymers are identified, whereas only one single signal is present in the voltammograms of the BCP. In addition, no signs of release of materials from the electrode surface were observed upon CV experiments of the BCP.

\section{Morphology}

Atomic force microscopy (AFM) was used to further verify whether the product obtained in the copolymerization of 5 and 7 is a BCP or a blend. Fig. 5 compares the AFM topography and phase images of thin films obtained by spin-coating of the P3HT and PDTS homopolymer, their physical blend and the BCP. The P3HT homopolymer films show a typical network of a few nanometer thick fibres, ${ }^{\mathbf{5 0}, 51}$ whereas PDTS films have a granular morphology with features around $30 \mathrm{~nm}$ to $50 \mathrm{~nm}$ in diameter. As such, the homopolymers possess very characteristic and easily recognizable morphologies. Interestingly, the thin films of the blend have characteristic features of both homopolymers. Granular structures presumably presenting PDTS embedded into a fibrous

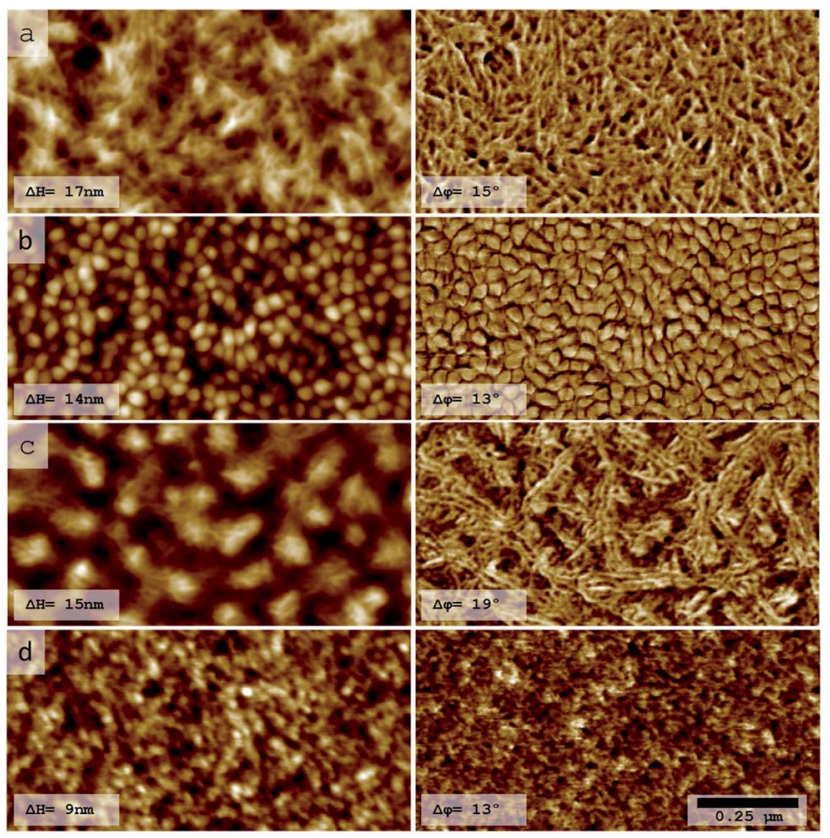

Fig. 5 AFM height and phase images of thin films of P3HT macroinitiator (a), PDTS (b), P3HT:PDTS blend (c) and P3HT- $b$-PDTS (d) spincoated from chlorobenzene solution $\left(c=3 \mathrm{~g} \mathrm{~L}^{-1}\right)$ on Si substrates at $1000 \mathrm{rpm}$ for $20 \mathrm{~s}$ and subsequent film drying.

network generated by the P3HT component. The P3HT:PDTS blend shows distinct separation of the two polymer phases.

The morphology of the block copolymer films differs significantly from the morphology of the blend and no macrophase separation into two domains is visible. Comparing the block copolymer with the respective homopolymer films, it is evident that the highly semicrystalline character of the P3HT block seems to become somehow weaker and only after thermal annealing fibrous features characteristic for P3HT become visible (Fig. S9 $\dagger$ ). The P3HT- $b$-PDTS crystallization in films seems to be dominated by the P3HT block. As such, AFM further additionally indicates the successful formation of the P3HT- $b$ PDTS block copolymer.

\section{Thermal analysis}

Similar to the electrochemical and morphological findings the thermal behavior of the BCP is dominated by the P3HT block as evidenced by Differential Scanning Calorimetry (DSC) (Fig. S5 $\dagger$ ). Both pure powder and precrystallized samples of the block copolymer show a melting transition at around $216{ }^{\circ} \mathrm{C}$ (Fig. S5a and $\left.\mathrm{b}^{\dagger}\right)$. The second heating cycle of the pure powder additionally shows a small endothermal peak at $224{ }^{\circ} \mathrm{C}$ (Fig. S5a $\dagger$ ). These thermal transitions can both be related to the P3HT macroinitiator which also shows a broad melting peak in the first cycle around $209{ }^{\circ} \mathrm{C}$ with a small shoulder at $216{ }^{\circ} \mathrm{C}$ for a precrystallized sample (Fig. S5c $\dagger$ ). A similar bimodal melting for P3HT homopolymer was previously observed by Lohwasser et al. and was explained in terms of a crystallization and subsequent recrystallization of $\mathrm{P}_{3} \mathrm{HT}^{52}$ In agreement with previous reports, ${ }^{\mathbf{1 3}}$ we could not find any transition in the DSC measurement for the PDTS homopolymer (Fig. S5d†). 


\section{Conclusion}

In conclusion, a zinc-organic monomer was prepared with near quantitative yield from a corresponding aryl dihalide by using BuLi as the activation agent followed by addition of $\mathrm{ZnCl}_{2}$. A quasi-living Negishi-type catalyst-transfer polycondensation (NCTP) was developed, which provides an access to narrowly distributed poly(4,4-bis(2-ethylhexyl)dithieno[3,2- $\left.b: 2^{\prime}, 3^{\prime}-d\right]$ silole) (PDTS) with controlled molecular weight. In contrast, the previously published methods which utilize Grignard activation reagents do not provide quantitative formation of the $\mathrm{Mg}$ organic DTS-based monomer which most likely accounts to worse polymerization performance of the Kumada versus Negishi catalyst-transfer polycondensations. The synthesis of series of well-defined PDTS-containing all-conjugated diblock copolymers with different block lengths was accomplished by a combination of Kumada and Negishi catalyst-transfer polycondensations. Particularly, it was shown that living P3HT chains obtained by KCTP of magnesium-organic thiophenebased monomer efficiently initiate NCTP of zinc-organic DTSbased monomer. A combination of physico-chemical methods was used to prove the success of the block copolymerization. This result enriches the catalyst-transfer polycondensation toolbox as it shows compatibility of different cross-couplings methods in the synthesis of all-conjugated block copolymers. Preliminary studies performed in our lab show that the developed Negishi polycondensation protocol which uses $\mathrm{BuLi} / \mathrm{ZnCl}_{2}$ as the activation agent is also applicable for controlled polycondensation of other relatively inactive aryl dihalides, such as dibromo-carbazoles..$^{53}$

\section{Acknowledgements}

This work is partly supported by the German Research Foundation (DFG) within the Cluster of Excellence 'Center for Advancing Electronics Dresden' (cfAED) and within SPP 1355 "Elementary Processes of Organic Photovoltaics", grant KI-1094/4". J. B., A. R. and S. L. acknowledge funding from the EU within Smartonics and the DFG within the Emmy Noether Program. We also thank F. Fischer and Dr D. Wang (Institute of Polymer Chemistry, University Stuttgart) for the HT-SEC measurements.

\section{Notes and references}

1 N. C. Greenham, S. C. Moratti, D. D. C. Bradley, R. H. Friend and A. B. Holmes, Nature, 1993, 365, 628.

2 R. H. Friend, R. W. Gymer, A. B. Holmes, J. H. Burroughes, R. N. Marks, C. Taliani, D. D. C. Bradley, D. A. D. Santos, J. L. Bredas, M. Logdlund and W. R. Salaneck, Nature, 1999, 397, 121.

3 J.-F. Morin, P.-L. Boudreault and M. Leclerc, Macromol. Rapid Commun., 2002, 23, 1032.

4 A. C. Grimsdale, K. C. Leok, R. E. Martin, P. G. Jokisz and A. B. Holmes, Chem. Rev., 2009, 109, 897.

5 S. Günes, H. Neugebauer and N. S. Sariciftci, Chem. Rev., 2007, 107, 1324.
6 J. Hou, H.-Y. Chen, S. Zhang, G. Li and Y. Yang, J. Am. Chem. Soc., 2008, 130, 16144.

7 T.-Y. Chu, J. Lu, S. Beaupré, Y. Zhang, J.-R. Pouliot, S. Wakim, J. Zhou, M. Leclerc, Z. Li, J. Ding and Y. Tao, J. Am. Chem. Soc., 2011, 133, 4250.

8 E. J. Meijer, D. M. de Leeuw, S. Setayesh, E. van Veenendaal, B. H. Huisman, P. W. M. Blom, J. C. Hummelen, U. Scherf and T. M. Klapwijk, Nat. Mater., 2003, 2, 678.

9 H. Bronstein, Z. Chen, R. S. Ashraf, W. Zhang, J. Du, J. R. Durrant, P. S. Tuladhar, K. Song, S. E. Watkins, Y. Geerts, M. M. Wienk, R. A. J. Janssen, T. Anthopoulos, H. Sirringhaus, M. Heeney and I. McCulloch, J. Am. Chem. Soc., 2011, 133, 3272.

10 A. Facchetti, Chem. Mater., 2011, 23, 733.

11 H.-R. Tseng, L. Ying, B. B. Y. Hsu, L. A. Perez, C. J. Takacs, G. C. Bazan and A. J. Heeger, Nano Lett., 2012, 12, 6353.

12 U. Scherf, A. Gutacker and N. Koenen, Acc. Chem. Res., 2007, 41, 1086.

13 G. Lu, H. Usta, C. Risko, L. Wang, A. Facchetti, M. A. Ratner and T. J. Marks, J. Am. Chem. Soc., 2008, 130, 7670.

14 L. Liao, L. Dai, A. Smith, M. Durstock, J. Lu, J. Ding and Y. Tao, Macromolecules, 2007, 40, 9406.

15 P. M. Beaujuge, W. Pisula, H. N. Tsao, S. Ellinger, K. Müllen and J. R. Reynolds, J. Am. Chem. Soc., 2009, 131, 7514.

16 J. Ohshita, D. Hamamoto, K. Kimura and A. Kunai, J. Organomet. Chem., 2005, 690, 3027.

17 It should be mentioned that a good progress was achieved in the step-growth synthesis of all-conjugated block copolymers: S.-Y. Ku, M. A. Brady, N. D. Treat, J. E. Cochran, M. J. Robb, E. J. Kramer, M. L. Chabinyc and C. J. Hawker, J. Am. Chem. Soc., 2012, 134, 16040.

18 E. E. Sheina, J. Liu, M. C. Iovo, D. W. Laird and R. D. McCullough, Macromolecules, 2004, 37, 3526.

19 I. Osaka and R. D. McCullough, Acc. Chem. Res., 2008, 41, 1202.

20 A. Yokoyama, R. Miyakoshi and T. Yokozawa, Macromolecules, 2004, 37, 1169.

21 T. Yokozawa and A. Yokoyama, Chem. Rev., 2009, 109, 5595.

22 Y. Geng, L. Huang, S. Wu and F. Wang, Sci. China: Chem., 2010, 53, 1620.

23 K. Okamoto and C. K. Luscombe, Polym. Chem., 2011, 2, 2424.

24 E. L. Lanni and A. J. McNeil, J. Am. Chem. Soc., 2009, 131, 16573.

25 A. Kiriy, V. Senkovskyy and M. Sommer, Macromol. Rapid Commun., 2011, 32, 1503.

26 R. Tkachov, V. Senkovskyy, H. Komber and A. Kiriy, Macromolecules, 2011, 44, 2006.

27 J. Hollinger, A. A. Jahnke, N. Coombs and D. S. Seferos, J. Am. Chem. Soc., 2010, 132, 8546.

28 (a) R. Miyakoshi, A. Yokoyama and T. Yokozawa, Chem. Lett., 2008, 37, 1022; (b) A. Yokoyama, A. Kato, R. Miyakoshi and T. Yokozawa, Macromolecules, 2008, 41, 7271.

29 S. Wu, L. Bu, L. Huang, X. Yu, Y. Han, Y. Geng and F. Wang, Polymer, 2009, 50, 6245.

30 A. E. Javier, S. R. Varshney and R. D. McCullough, Macromolecules, 2010, 43, 3233. 
31 L. Huang, S. Wu, Y. Qu, Y. Geng and F. Wang, Macromolecules, 2008, 41, 8944.

32 (a) Y.-C. Lai, K. Ohshimizu, A. Takahashi, J.-C. Hsu, T. Higashihara, M. Ueda and W.-C. Chen, J. Polym. Sci., Part A: Polym. Chem., 2011, 49, 2577; (b) F. Ouhib, A. Khoukh, J.-B. Ledeuil, H. Martinez, J. Desbrieres and C. Dagron-Lartigau, Macromolecules, 2008, 41, 9736-9743; (c) Y. Zhang, K. Tajima, K. Hirota and K. Hashimoto, J. Am. Chem. Soc., 2008, 130, 7812.

33 E. F. Palermo and A. J. McNeil, Macromolecules, 2012, 45, 5948.

34 V. Senkovskyy, N. Khanduyeva, H. Komber, U. Oertel, M. Stamm, D. Kuckling and A. Kiriy, J. Am. Chem. Soc., 2007, 129, 6626.

35 V. Senkovskyy, R. Tkachov, T. Beryozkina, H. Komber, U. Oertel, M. Horecha, V. Bocharova, M. Stamm, S. A. Gevorgyan, F. C. Krebs and A. Kiriy, J. Am. Chem. Soc., 2009, 131, 16445.

36 N. Marshall, S. K. Sontag and J. Locklin, Chem. Commun., 2011, 47, 5681 .

37 (a) V. Senkovskyy, R. Tkachov, H. Komber, M. Sommer, M. Heuken, B. Voit, W. T. S. Huck, V. Kataev, A. Petr and A. Kiriy, J. Am. Chem. Soc., 2011, 133, 19966; (b) V. Senkovskyy, R. Tkachov, H. Komber, A. John, J.-U. Sommer and A. Kiriy, Macromolecules, 2012, 45, 7770.

38 T. Erdmann, Synthese von Dithienosilol-basierten Halbleiterpolymeren für die organische Elektronik, Master thesis, 2013.

39 F. Boon, N. Hergué, G. Deshayes, D. Moerman, S. Desbief, J. De Winter, P. Gerbaux, Y. H. Geerts, R. Lazzaroni and P. Dubois, Polym. Chem., 2013, 4, 4303.

40 P. Willot, S. Govaerts and G. Koeckelberghs, Macromolecules, 2013, 46, 8888.
41 Y. A. Getmanenko, P. Tongwa, T. V. Timofeeva and S. R. Marder, Org. Lett., 2010, 12, 2136.

42 (a) A. Krasovskiy and P. Knochel, Angew. Chem., Int. Ed., 2004, 43, 3333; (b) M. C. Stefan, A. E. Javier, I. Osaka and R. D. McCullough, Macromolecules, 2009, 42, 30.

43 R. H. Lohwasser and M. Thelakkat, Macromolecules, 2011, 44, 3388.

44 R. Tkachov, V. Senkovskyy, H. Komber, J.-U. Sommer and A. Kiriy, J. Am. Chem. Soc., 2010, 132, 7803.

45 J. Clark, J.-F. Chang, F. C. Spano, R. H. Friend and C. Silva, Appl. Phys. Lett., 2009, 94, 163306.

46 E. J. W. Crossland, K. Rahimi, G. Reiter, U. Steiner and S. Ludwigs, Adv. Funct. Mater., 2011, 21, 518.

47 G. Gritzner and J. Kuta, Pure Appl. Chem., 1984, 4, 461.

48 J. Heinze, B. A. Frontana-Uribe and S. Ludwigs, Chem. Rev., 2010, 110, 4724.

49 C. M. Cardona, W. Li, A. E. Kaifer, D. Stockdale and G. C. Bazan, Adv. Mater., 2011, 23, 2367.

50 R. Zhang, B. Li, M. C. Iovu, M. Jeffries-EL, G. Sauvé, J. Cooper, S. Jia, S. Tristram-Nagle, D. M. Smilgies, D. N. Lambeth, R. D. McCullough and T. Kowalewski, J. Am. Chem. Soc., 2006, 128, 3480.

51 M. Brinkmann, J. Polym. Sci., Part B: Polym. Phys., 2011, 49, 1218.

52 R. H. Lohwasser and M. Thelakkat, Macromolecules, 2012, 45, 3070 .

53 Turbo-Grignard reagent $i$-PrMgCl$\cdot \mathrm{LiCl}$ fails to activate dibromocarbazole and only short oligomers are formed in polymerization of dibromocarbazole by using, as activation agent, more reactive lithium tributylmagnesate (n$\left.\mathrm{Bu}_{3} \mathrm{MgLi}\right)$ : M. C. Stefan, A. E. Javier, I. Osaka and R. D. McCullough, Macromolecules, 2009, 42, 30. 